\title{
Pulmonary Hypertension in Hemodialysis Patients
}

\author{
M Moniruzzaman', MN Islam², MB Alam ${ }^{3}$, A.B.M. M Alam³, MMH Khan², \\ Z ALI ${ }^{4}$, AW Chowdhury ${ }^{5}$, MN Chowdhury ${ }^{6}$ \\ ${ }^{1}$ Department of Nephrology, United Hospital Limited, Dhaka. ${ }^{2}$ Department of Nephrology, Dhaka \\ Medical College, Dhaka. ${ }^{3}$ Department of Nephrology, National Institute of Kidney Diseases and \\ Urology, Dhaka. ${ }^{4}$ Department of Cardiology, NICVD, Dhaka. ${ }^{5}$ Department of Cardiology, Dhaka \\ Medical College. ${ }^{6}$ Department of Nephrology, National Institute of diseases of the Chest and Hospital
}

Key words:

Chronic kidney

disease,

Pulmonary

Hypertension, Haemodialysis.

\begin{abstract}
:
Background: Pulmonary hypertension (PH) has been reported to be high among maintenance dialysis patients. There is a paucity of data on the incidence and prevalence of pulmonary hypertension in chronic kidney disease(CKD) in Bangladeshi patients.

Materials and Methods: A total 70 CKD patients (male 47,female 23), who were on conservative management and maintenance hemodialysis were studied for the presence of pulmonary hypertension. The variables studied were hypertension, diabetes, duration of dialysis and the hemoglobin, serum creatinine and serum bicarbonate levels.
\end{abstract}

Results: $68.6 \%$ of the patients on maintenance hemodialysis had pulmonary hypertension compared to $8.6 \%$ of the prediadysis CKD patients. $97.1 \%$ of maintenance dialysis patients had anaemia (Hb $<10 \mathrm{gm} / \mathrm{dl}$ ) and $42.9 \%$ of patients had metabolic acidosis.

Conclusion: The incidence of pulmonary hypertension was highest in the hemodialysis group. Significant Pearson's correlation was found between pulmonary arterial systolic pressure with the duration of hemodialysis, hemoglobin level, serum creatinine, blood sugar and serum bicarbonate level in maintenance hemodialysis patients

(Cardiovasc. j. 2012; 4(2): 148-152)

\section{Introduction:}

Chronic kidney disease (CKD) leads to many co morbidities that affect patients of all stages of the disease. The complications of CKD are due to the disease itself as well as the mode of renal replacement therapy (RRT). Kidney function can only be partly replaced by maintenance dialysis, which provides only $5-10 \%$ of excretory renal function. ${ }^{1}$ At present out of three modalities of treatment -conservative management, hemodialysis (HD) and peritoneal dialysis, maximum patients are on $\mathrm{HD} .^{2}$ Cardio vascular morbidity and mortality is highest in the dialysis population. Recently an association has been found between RRT and the development of pulmonary hypertension.

The presence of $\mathrm{PH}$ may reflect serious pulmonary vascular disease, which can be progressive and fatal. Consequently, an accurate diagnosis of the cause of $\mathrm{PH}$ is essential in order to establish an effective treatment program. Pulmonary hypertension can occur from diverse etiologies. The most common causes of $\mathrm{PH}$ are left heart failure and chronic hypoxic lung diseases. Less commonly, $\mathrm{PH}$ occurs in distinct clinical conditions such as collagen vascular disease, chronic recurrent thromboembolism, portal hypertension, human immunodeficiency virus (HIV) infection, hematological conditions, following exposure to drugs and toxins, etc. Regardless of etiology, $\mathrm{PH}$ increases morbidity and mortality. Moreover, the presence of $\mathrm{PH}$ in systemic disorders increases mortality rates beyond the expected and sometimes is the leading cause of mortality.

In 1996 Mordechai Yigla first noted unexplained $\mathrm{PH}$ in some long- term hemodialysis (HD) patients during an epidemiological study of this disorder. It was assumed that their PH was related to end stage renal disease (ESRD) or to long term HD therapy via an arteriovenous (AV) access.

Address of correspondence: Dr Mohammad Moniruzzaman, Specialist, Department of Nephrology, United Hospital Limited, Gulshan, Dhaka, Bangladesh. 
Despite almost five decades of HD therapy via a surgically created, often large, hemodynamically significant $A V$ access, the long-term impact of this intervention on pulmonary circulation has received little attention. The development of pulmonary hypertension in ESRD patients is associated with increased morbidity and mortality. There is non-invasive technique like Doppler echocardiography to detect pulmonary hypertension; so early diagnosis by Doppler echocardiography enables timely intervention, currently limited to changing dialysis modality or referring for kidney transplantation. Even then there is paucity of data on the incidence and prevalence of $\mathrm{PH}$ in chronic kidney disease in Bangladeshi patients.

\section{Materials and Methods}

This cross-sectional study was carried out in the Department of Nephrology, Dhaka Medical College Hospital from January 2010 to December 2010. A total 70 patients were included in the study out of which 35 patients on maintenance hemodialysis $\&$ predialysis CKD patients was 35 .

All the participants history was taken, physical examination was done and necessary investigation was carried out. Blood pressure was recorded at least after 5 minutes rest being relaxed on a chair with a support on the back keeping bared arm on a table at heart level. A conventional sphygmomanometer was used covering more than $80 \%$ of arm by bladder. Patients estimated glomerular filtration rate (eGFR) was calculated by using Cockroft-Gault (CG) formula-

$\mathrm{eGFR}=\frac{[140-\text { age }(\mathrm{yrs}) \times \text { body wt }(\mathrm{kg})]}{\text { Serum creatinine }(\mathrm{mg} / \mathrm{dl}) \times 72}$

Multiply by 0.85 in female to correct for reduced creatinine production.

Then all patients have a Doppler echocardiogram done by an experienced cardiologist. In the maintenance hemodialysis group the Doppler echocardiography done on the day after hemodialysis to overcome the volume overload. Pulmonary arterial systolic pressure can be measured non-invasively by tricuspid regurgitation jet method by Doppler echocardiogram. The aim is to measure PASP (Pulmonary arterial systolic pressure) assuming no pulmonary valvular stenosis, and then this is equal to right ventricular systolic pressure (RVSP).

RVSP can be easily estimated from the maximum velocity of the tricuspid regurgitation jet $\left(\mathrm{V}_{\mathrm{TR}}\right)$. The pressure gradient between the right atrium and the right ventricle across the tricuspid valve (RVSPRAP) can be estimated by the Bernoulli equation using the maximum $\mathrm{V}_{\mathrm{TR}}$.

$$
\text { RVSP-RAP }=4 \mathrm{~V}_{\mathrm{TR}}{ }^{2}
$$

The value of RAP (right atrial pressure) is known. It is equal to the jugular venous pressure (JVP) which can be assessed clinically (in healthy individuals and is usually $0-5 \mathrm{~cm}$ of blood, measured from the sternal angle, and $1 \mathrm{~cm}$ of blood is almost equal to $1 \mathrm{mmHg}$.)

This allows us to estimate that:

$$
\mathrm{PASP}=\mathrm{RVSP}=4 \mathrm{~V}_{\mathrm{TR}}{ }^{2}+\mathrm{JVP} / \mathrm{or}, \mathrm{RAP}
$$

For estimation of hemoglobin, serum creatinine, blood sugar and serum bicarbonate venous blood samples were collected by sterile disposable syringe with strict aseptic precaution. For estimation of blood sugar $2 \mathrm{cc}$ of blood was poured to blood sugar bottle and 3 cc blood was kept in syringe for estimation of hemoglobin, serum creatinine and serum bicarbonate. All samples sent immediately to clinical pathology, DMCH. Serum creatinine was estimated using kinetic model; blood sugar was estimated by Glucose oxidase method. Echocardiography was done by colour Doppler Echocardiographic Equipment model GE system five by GE Vingmed ultrasound, Norway.

The relationship of all the variables to pulmonary hypertension in CKD was assessed by Pearson's correlation coefficient. All data was analyzed by using computer based SPSS (Statistical Program for Social Science) program.

\section{Observation and Results}

In our study 70 patients were included of whom 35 patients on maintenance hemodialysis and rest 35 patients on predialysis CKD patients which are categorized as Group I and Group II respectively. The male/female ratio was almost 2:1. Most of the patients belongs to 30 to 40 years age range in both group.

The scatter diagram shows significant relationship $(\mathrm{r}=0.424)$ between pulmonary arterial systolic 


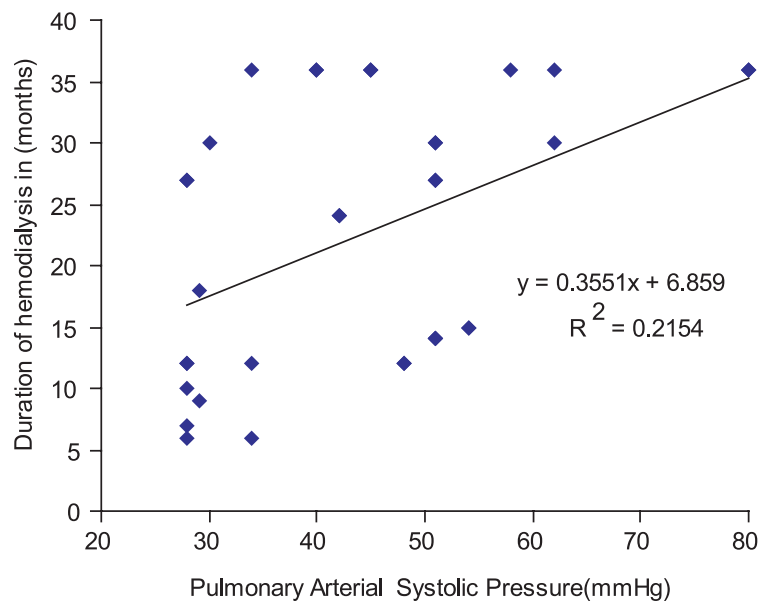

Fig 1: Correlation between pulmonary arterial systolic pressure ( $\mathrm{mmHg}$ ) with duration of hemodialysis (in months) of the study patients $(n=35)$

pressure $(\mathrm{mmHg})$ with duration of hemodialysis (months) in group I patients $(\mathrm{n}=35)$.

In this study it was found that $68.6 \%$ of group I and $8.6 \%$ of group II patients had pulmonary hypertension. Mild pulmonary hypertension was found in $22.9 \%$, moderate and severe pulmonary hypertension was found in $40 \%$ and $5.7 \%$ respectively. However only $8.6 \%$ patients had mild pulmonary hypertension in group II patients. The mean pulmonary arterial systolic pressure (PASP) was $44.1 \pm 14.4 \mathrm{mmHg}$ with range from 28 to 80 $\mathrm{mmHg}$ in group I. In group II the mean PASP was $28.9 \pm 4.1 \mathrm{mmHg}$ with range from 24 to $38 \mathrm{mmHg}$. The mean PASP difference was statistically significant $(p<0.05)$ in unpaired t-test.

Significant Pearson's correlation was found between pulmonary arterial systolic pressure with the duration of hemodialysis $(\mathrm{r}=0.424 ; \mathrm{p}=0.023)$, hemoglobin level $(\mathrm{r}=-0.539 ; \mathrm{p}=0.001)$, serum creatinine $(r=0.568 ; p=0.001)$, blood sugar $(r$ $=0.535 ; \mathrm{p}=0.001)$ and serum bicarbonate level $(\mathrm{r}=-$ $0.470 ; p=0.003)$ in group I patients.

In group II patients no correlation were found in Serum Creatinine, Hemoglobin, Blood sugar and Serum bicarbonate level with pulmonary arterial systolic pressure, which were $\mathrm{r}=0.195 ; \mathrm{p}=0.636$, $\mathrm{r}=0.199 ; \mathrm{p}=0.251, \mathrm{r}=0.161 ; \mathrm{p}=0.326$ and $\mathrm{r}=0.282$; $\mathrm{p}=0.133$ respectively.

\section{Table I}

Shows mean Pulmonary Arterial Systolic Pressure $(\mathrm{mm} \mathrm{Hg})$ distribution of the study patient ( $n=70)$.

\begin{tabular}{|c|c|c|c|c|c|}
\hline \multirow[t]{2}{*}{$\overline{\mathrm{PASP}}(\mathrm{mm} \mathrm{Hg})$} & \multicolumn{2}{|c|}{ Group I(n=35) } & \multicolumn{2}{|c|}{ Group II $(n=35)$} & \multirow[t]{2}{*}{ PValue } \\
\hline & $\mathrm{n}$ & $\%$ & $\overline{\mathrm{n}}$ & $\%$ & \\
\hline Normal (£30 mmHg) & 11 & 31.4 & 32 & 91.4 & \\
\hline \multicolumn{6}{|l|}{ High $(\mathrm{PASP})>30 \mathrm{mmHg}$} \\
\hline Mild (31-45 mmHg) & 8 & 22.9 & 3 & 8.6 & \\
\hline Moderate $(46-65 \mathrm{mmHg})$ & 14 & 40.0 & 0 & 0.0 & \\
\hline Severe (>65 mmHg) & 2 & 5.7 & 0 & 0.0 & \\
\hline Mean_SD & 44.1 & \pm 14.4 & 28.9 & \pm 4.1 & $0.001^{\mathrm{S}}$ \\
\hline Range (min - max) & $(28$ & $-80)$ & $(24$ & $-38)$ & \\
\hline
\end{tabular}

$\mathrm{S}=$ Significant

$\mathrm{P}$ value reached from unpaired ' $\mathrm{t}$ ' test

Table-II

Correlation of different parameters with pulmonary arterial systolic pressure of the study patients $(n=70)$

\begin{tabular}{|c|c|c|c|c|}
\hline & \multicolumn{2}{|c|}{ Group I(n=35) } & \multicolumn{2}{|c|}{ Group II $(\mathrm{n}=35)$} \\
\hline & $\begin{array}{c}\text { Correlation } \\
\text { coefficient }\end{array}$ & $\mathrm{P}$ value & $\begin{array}{c}\text { Correlation } \\
\text { coefficient }\end{array}$ & $P$ value \\
\hline Duration of hemodialysis in (months) & 0.424 & $0.023^{\mathrm{s}}$ & - & - \\
\hline Hemoglobin (gm/dl) & -0.539 & $0.001^{\mathrm{s}}$ & 0.199 & $0.251^{\mathrm{ns}}$ \\
\hline Serum Creatinine (mg/dl) & 0.568 & $0.001^{\mathrm{s}}$ & 0.195 & $0.636^{\mathrm{ns}}$ \\
\hline Blood sugar 2h ABF (mmol/L) & 0.535 & $0.001^{\mathrm{s}}$ & 0.161 & $0.326^{\mathrm{ns}}$ \\
\hline Serum bicarbonate level (mmol/L) & -0.470 & $0.003^{\mathrm{s}}$ & 0.282 & $0.133^{\mathrm{ns}}$ \\
\hline
\end{tabular}

$\mathrm{p}$ value reached from Pearson's correlation 


\section{Disscusion:}

An echocardiography diagnosis of pulmonary hypertension $(\mathrm{PH})$ is made when systolic pulmonary arterial pressure (PAP) exceeds normal values $(30 \mathrm{mmHg})$. In mild $\mathrm{PH}$, values ranges up to $45 \mathrm{mmHg}$, in moderate $\mathrm{PH}, \mathrm{PAP}$ is between 45 and $65 \mathrm{mmHg}$ and in severe $\mathrm{PH}, \mathrm{PAP}$ values are greater than $65 \mathrm{mmHg}$. Systolic PAP equals cardiac output times pulmonary vascular resistance (PVR), (i.e., $\mathrm{PAP}=$ cardiac output $\times \mathrm{PVR}$ ). Increased cardiac output by itself does not cause $\mathrm{PH}$ because of the enormous capacity of the pulmonary circulation to accommodate the increase in blood flow. Therefore development of $\mathrm{PH}$ requires marked elevation of pulmonary vascular resistance.

There are several potential explanations for the development of $\mathrm{PH}$ in patients with ESRD. Hormonal and metabolic derangement associated with ESRD might lead to vasoconstriction of pulmonary vessels and increased pulmonary vascular resistance. ${ }^{3}$ Values of PAP may be further increased by high cardiac output resulting from the AV access itself, ${ }^{4}$ worsened by commonly occurring renal anemia and fluid overload. Medical conditions with shunting of blood from the left to the right side of the heart and increased cardiac output and pulmonary blood flow, such as congenital heart disease, are well recognized as possible causes of PH. ${ }^{5,6}$

Excess mortality rates due to cardiovascular disease in end-stage renal disease (ESRD) patients had been described by epidemiological and clinical studies. It accounts for approximately 50 percent of deaths in dialysis patients. Although controversial, this may be due in part the presence of excess vascular calcification, particularly in the form of extensive coronary artery calcification, which can be observed even in very young dialysis patients. It was suggested that abnormalities of the right ventricular function in patients with ESRD were largely due to pulmonary hypertension, which usually develops secondary to pulmonary artery calcifications. ${ }^{7}$

In the present study it was observed that the mean age was $39.5 \pm 10.3$ years and $42.5 \pm 12.8$ years in group I and II respectively ( $>0.05$ ). Male was predominant in both groups and male female ratio was almost $2: 1$ in the whole study patients.
HTN was observed in $85.7 \%$ and $71.4 \%$ in group I and group II respectively ( $\mathrm{p}=0.145)$. DM was present $20.0 \%$ in group I and $22.9 \%$ in group II (p $=0.770)$.

Majority (42.9\%) of the patients had 13-24 months of hemodialysis and the mean duration of hemodialysis was $22.9 \pm 10.4$ months with range from 6 to 36 months.

Pulmonary hypertension was found $68.6 \%$ (24) on maintenance hemodialysis patients whereas only $8.6 \%$ (3) in predialysis CKD patients. The mean systolic pulmonary arterial pressure (PAP) was $44.1 \pm 14.4 \mathrm{mmHg}$ with range from 28 to $80 \mathrm{mmHg}$ in group I. In group II the mean systolic PAP was $28.9 \pm 4.1 \mathrm{mmHg}$ with range from 24 to $38 \mathrm{mmHg}$. The mean systolic PAP was significantly $(\mathrm{p}<0.05)$ higher in group I patients.

In this study it was observed that $97.1 \%$ and $74.3 \%$ patients had anaemia $(<10 \mathrm{gm} / \mathrm{dl}$ hemoglobin) in group I and group II respectively $(p=0.001)$. The mean hemoglobin was $8.7 \pm 0.7 \mathrm{gm} / \mathrm{dl}$ in group I and $9.5 \pm 0.9 \mathrm{gm} / \mathrm{dl}$ in group II $(\mathrm{p}=0.001)$.

The mean serum creatinine was $9.4 \pm 1.5$ and $5.1 \pm 1.3$ $\mathrm{mg} / \mathrm{dl}$ in group I and group II respectively. The mean blood sugar $2 \mathrm{~h} \mathrm{ABF}$ was $6.7 \pm 1.2 \mathrm{mmol} / \mathrm{L}$ in group I and $5.6 \pm 0.3 \mathrm{mmol} / \mathrm{L}$ in group II. The mean hemoglobin level was significantly $(\mathrm{p}<0.05)$ higher in group II but the mean S. creatinine and blood sugar $2 \mathrm{~h} A B F$ were significantly $(\mathrm{p}<0.05)$ higher in group I.

Regarding the serum bicarbonate level $42.9 \%$ and $17.1 \%$ in group I and group II patients had metabolic acidosis, which was significant $(p<0.05)$ between the two groups.

In group I patients significant Pearson's correlation were found between pulmonary arterial pressure with duration of hemodialysis $(\mathrm{r}=0.424 ; \mathrm{p}=0.023)$, hemoglobin level ( $\mathrm{r}=-0.539 ; \mathrm{p}=0.003)$ creatinine $(\mathrm{r}=0.568 ; \mathrm{p}=0.001)$ blood sugar $(2 \mathrm{~h} \mathrm{ABF})(\mathrm{r}=0.535$; $\mathrm{p}=0.001)$ and serum bicarbonate level $(\mathrm{r}=-0.470$; $\mathrm{p}=0.001$, ).

In group II patients no significant correlation were found between pulmonary arterial pressure with hemoglobin level, creatinine, blood sugar (2h ABF) and serum bicarbonate level.

The study demonstrates that CKD patients on maintenance hemodialysis are significantly more likely to develop pulmonary hypertension. 


\section{Conclusion:}

This study demonstrated that $68.6 \%$ of patients with $\mathrm{CKD}$ on MHD have $\mathrm{PH}$ which is much higher value compared to other study. The sample size of this study is relatively small, and for this reason, multicenter studies are required. PAP was noninvasively measured by Doppler echocardiography without right heart catheterization. Since followup of this study was not done to evaluate the effect of pulmonary hypertension on morbidity and mortality, long-term follow-up of patients with pulmonary hypertension is needed.

\section{References:}

1. Gokul R. Replacement therapy by dialysis. In: Weatherall DJ, Ledingham JG, Warrell DA. Eds. Oxford textbook of medicine, $3^{\text {rd }}$ ed. Oxford;Oxford University Press, 1996: 3306- 3310.

2. Yigla M, Dabbah S, Azzam ZS, Rubin AH. Reisner SA: Background diseases in 671 patients with moderate to severe pulmonary hypertension. Isr Med Assoc J 2000; 2: 684-689.

3. Moris ST, Jardine AG. The vascular endothelium in chronic renal failure. $J$ Nephrol 2000; 13: 96-105.

4. Savage MT,Ferro CJ, Sassano A, Thomson CR. The impact of arterious fistula formation on central hemodynamic pressure in chronic renal failure patients:a prospective study. Am J kidney Dis 2002; 40: 753-759.

5. Dschietzig T, Richter C, Bartsch C, Bohme C, Heinze D, Ott F, Zartnack F, Baumann G, Stangl K. Flowinduced pressure differentially regulates endothelin1 urotensin 11, adrenomedullin, and relaxin in pulmonary vascular endothelium. Biochem biophys res commun 2001, 89 :245-251.

6. Michel RP, Hakim TS, Hanson RE, Dobell AR, Keith F, Drink water D. Distribution of lung vascular resistance after chronic systemic-to-pulmonary shunts. Am J Physiol 1985; 249: 1106-1113.

7. S Mahdavi-Mazdeh M, Alijavad-Mousavi S, Yahyazadeh H, Azadi M, Yoosefinejad H, Ataiipoor Y. Pulmonary
Hypertension in Hemodialysis Patients. Saudi J Kidney Dis Transpl 2008; 19 :189-193.

8. Dagli CE, Sayarlioglu H, Dogan E, Acar G, Demirpolat G, Ozer A, Koksal N, Gelen ME, Atilla N, Tanrikulu AC, Isik IO, Ugur T. Prevalence of and Factors Affecting Pulmonary Hypertension in Hemodialysis Patients. Respiration 2009; 78 : 411-415.

9. Floege Jurgen and Ketteler M. Vascular calcification in patients with end-stage renal disease. Nephrol Dial Transplant 2004; 19 : V59-v66.

10. Galie N, Torbicki A, Barst R, Dartevelle P, Hawotrh S. Guidelines on diagnosis and treatment of pulmonary arterial hypertension. European Heart Journal 2009; $30: 2493-2537$.

11. Nakhoul F, Yigla M, Gilman R, Reisner SA, Abassi Z. Pathogenesis of pulmonary hypertension in haemodialysis patients via arterio-venous access. Nephrol Dial Transplant 2005; 20 :1686-1692.

12. Pastan S, Bailey J. Dialysis therapy. N Engl J Med 1998; 338 :1428-1437.

13. Patel P, G. Abraham, B. Pratap, R. Ramalakshmi, M. Mathew, J. M. Jeevan, T. R. Muralidharan, A. Moorthy, N. Leslie. Clinical and biochemical parameters in chronic kidney disease with pulmonary hypertension. Indian Journal of Nephrology 2007;17 : 4-6.

14. Tarrass F, Benjelloun M, Hachim K, Benghanem MG, Ramdani B. Pulmonary hypertension in patients with end-stage renal disease. Indian J Nephrol 2005; 15 : 223-226.

15. Tarrass F, Benjelloun M, Medkouri G, Hachim K, Benghanem MG, Ramdan B. Doppler echocardiograph evaluation of pulmonary hypertension in patients undergoing hemodialysis. Hemodialysis International 2006; $10: 356-359$.

16. Yigla M, Abassi Z, Reisner SA and Nakhoul F.Pulmonary Hypertension in Hemodialysis Patients: An Unrecognized Threat. Seminars in Dialysis 2006; 19 : 353-357.

17. Yigla M, Keidare Z, Safadi I, Tov N, Reisner SA, Nakhoul F. Pulmonary calcification in hmodialysis patients: correlation with pulmonary artery pressure values. Kidney Int 2004; 66 : 806-810. 